Supporting Information for:

\title{
Theoretical Evidence for Multiple Charge Transfer Pathways in Bacteriorhodopsin
}

Choongkeun Lee and Blake Mertz*

C. Eugene Bennett Department of Chemistry, West Virginia University, Morgantown, WV 26506

*blake.mertz@mail.wvu.edu

Table S1. Energy difference at neutral and charged states of amino acids for reorganization energy $\left(E^{i}-E^{f}\right)$

\begin{tabular}{lrrrr}
\hline & \multicolumn{2}{c}{ electron } & \multicolumn{2}{c}{ hole } \\
\hline State & neutral & charged & neutral & charged \\
\hline ALA & 0.700 & 0.879 & 0.762 & 0.480 \\
ARG & 0.857 & 0.722 & 2.206 & 1.297 \\
ASN & 1.394 & 0.572 & 1.022 & 1.286 \\
ASP & 0.777 & 0.489 & 1.081 & 1.496 \\
GLN & 1.013 & 2.334 & 0.810 & 0.700 \\
GLU & 0.404 & 0.301 & 0.869 & 0.794 \\
GLY & 0.401 & 0.772 & 1.468 & 1.044 \\
ILE & 0.661 & 0.792 & 0.773 & 0.481 \\
LEU & 0.699 & 0.788 & 0.761 & 0.445 \\
LYS & 0.673 & 0.871 & 1.756 & 2.391 \\
MET & 0.238 & 0.189 & 0.941 & 0.626 \\
PHE & 0.444 & 0.381 & 0.373 & 0.398 \\
PRO & 0.478 & 0.724 & 0.832 & 0.510 \\
RET & 0.146 & 0.161 & 0.165 & 0.121 \\
SER & 0.736 & 0.670 & 0.759 & 0.453 \\
THR & 2.318 & 0.955 & 0.846 & 0.635 \\
TRP & 0.259 & 0.416 & 0.203 & 0.174 \\
TYR & 0.332 & 0.291 & 0.285 & 0.326 \\
VAL & 0.653 & 0.661 & 0.816 & 0.564 \\
\hline & & & &
\end{tabular}

